\title{
Software Patents and Open Source Software in the European Union: Evidences of a Trade-Off?
}

\author{
Francesco Rentocchini ${ }^{1}$ and Giuditta De Prato ${ }^{2}$ \\ 1 Department of Economics, University of Bologna, Italy \\ francesc.rentocchini @studio. unibo.it \\ ${ }^{2}$ Department of Economics, University of Bologna, Italy depratoespbo. unibo.it
}

\begin{abstract}
The present work aims at giving an account of the patenting behaviour in the software sector, focusing on the European Union and pointing out issues regarding a trade-off which would support a policy attitude in favour of a wider diffusion of the Open Source model.
\end{abstract}

\section{Introduction}

It is well known that art. 52 of the European Patent Convention regulates patenting activities within the Union and expressively do not allow software and business methods patentability. This exception is not completely applied in practice. In fact, more than 70,000 patents are found to have been accorded by the European Patent Office in the period 1982-2004. The aim of this paper is threefold: first, economic literature on patents is reviewed concentrating on more recent contributions; second, an original database for the European Union is constructed which links the number of software patents filed at the European Patent Office by European firms with their $R \& D$ spending and other relevant variables, and advanced econometric techniques for data counting are applied to find out the most relevant factors affecting the accorded software patents; finally, conclusions are drawn showing that support to Open Source Software (OSS) could help stimulating competition in the ICT sector and increasing the innovation rate, while in fact, on the other side, strategic patenting is confirmed by available data analysis.

\section{Recent Developments in the Theoretical Literature}

Since a long time, the economic literature has recognised the importance of the patent system in shaping and directing the rate of appropriation of the inmovative effort of the firm $[1,6]$. In addition to 'classical' contributions, the literature that has been developed to explain the recent trends in worldwide patenting, has relied on Schumpeter's contributions to economic thought [7]. More recently, evolutionary economics [5] has focused on the role of patents in enhancing or hindering innovation depending on sectors where firms compete. Therefore, a number of authors underlines that, depending on appropriability

Please use the following format when citing this chapter:

Rentocchini, F., and De Prato, G., 2006, in IFIP International Federation for Information Processing, Volume 203, Open Source Systems, eds. Damiani, E., Fitzgerald, B., Scacchi, W., Scotto, M., Succi, G., (Boston: Springer), pp. 349-351 
conditions of sectors in which they are used, patents might be, or not, a useful institutional mechanism in order to promote the variety of technological solutions and the selection by market forces via competition. In addition, empirical contributions have shown that firms do not always rate patents as effective appropriability mechanisms [3]. Hence, on one side, empirical literature shows how patents are not suitable appropriability mechanisms in a high number of sectors, but, on the other side, we witness an explosion in the number of patents filed in recent years. Why is there such a trade-off? Which factors contribute to explain it? One of the main reason refers to strategic patenting, which is a strategic behaviour of firms aimed at hindering competition, obtain licensing revenues and to have stronger power in negotiations.

\section{Data Collection and Econometric Analysis}

In order to analyse recent trends in software patenting in the European Union, we relied on the Gauss.ffi database. The subset of data relevant to the present work had been built by extracting and collecting all records regarding patents filed between January, 1st 1995 and December, 31st 2004, thus obtaining a total of 65.536 patent records. After that, a relation has been established between the collected dataset and the $2004 \mathrm{EU}$ Industrial Research Investment Scoreboard. The resulting dataset is composed by 1000 firms both European and non European whose data concerning Research and Development spending, FTSE sectoral classification and geographical classification, number of software patents filed at EPO, net sales, number of employees and operating profit and revenue are available for the period 2000-2003. Hence a panel dataset has been created with information on one thousand firms through a four year long time period (2000-2003). After that, econometric techniques have been applied in order to analyse more in deep the relationship between software patents and other variables in the dataset. Results show that $R \& D$ and size contribute to explain the number of software patents filed within this period. A second specification of the model is used to investigate sectoral differences in the number of software patents firms apply for. Results show that, in line with empirical studies conducted in US [2,4], only electronic and electrical and IT hardware industries are found to be highly significant in explaining the number of software patents filed during the period of consideration. Hence, it seems that software patents are principally filed by firms which do not have software production as primal activity. Electronic and IT hardware firms instead are found to rely disproportionally on software patenting.

\section{Which Role for the Open Source Software?}

Such conclusions coming from the data analysis are then put in relation to the support in principle accorded by the European Union to the Open Source model 
and to the fact that OSS demonstrated a potential in stimulating innovation and technological improvement. OSS is perceived as suitable to promote innovation to different extents, because free circulation of software makes progress results fully available and it provides incentives to users to innovate, to freely reveal and to diffuse innovations, making them affordable also to small enterprises. Early surveys showed OSS is likely to promote innovation among SMEs by lowering costs for knowledge appropriation and licences, while lack of information and proprietary innovation delay the process of innovation adoption. Along with similar arguments, the European Union declared a willingness to consolidate a dominant position in the Open Source environment, also in order to find a new role in the software sector. The paper therefore proposes some reflections, which could help to draw policy indications, on the limitations which the analysed patenting system could pose to the role of OSS in diffusing innovation, and on alternative strategies which EU Instititions could push forward to promote alternative methods of intellectual property protection involving -for exampleGPLs.

\section{References}

1. K. Arrow. Economic welfare and the allocation of resources for invention. In R. Nelson, editor, The Rate and Direction of Inventive Activity: Economic and Social Factors. NBER, Princeton University Press, 1962.

2. J. Bessen and R. Hunt. The software patent experiment. In Patents, Innovation and Economic Performance, pages 246-263. Organisation for Economic Cooperation and Development (OECD), April 2003.

3. W. Cohen, R. Nelson, and J. Walsh. Protecting their intellectual assets: Appropriability conditions and why U.S. manufacturing firms patent (or not). Working Paper 7552, 2000.

4. B. Hall. Exploring the patent explosion. Journal of Technology Transfer, 30(12):35-48, 2004.

5. R. Nelson and S. Winter. An Evolutionary Theory of Economic Change. Belknap press, 1982.

6. W. Nordhaus. Invention, Growth and Welfare. MIT Press, Cambridge Massachussets, 1969.

7. J. Schumpeter. Capitalism, Socialism and Democracy. McGraw Hill, 1942. 